\title{
Charge transport phenomena in thin-film cathodes
}

\author{
A.A. van Zomeren, J.-H. Koegler, J. Schoonman and P.J. v.d. Put \\ Laboratory for Inorganic Chemistry, Faculty of Chemical Technology and Materials Science, Delft University of Technology, \\ P.O. Box 5045, 2600 GA Delfi, The Netherlands
}

\begin{abstract}
The OCV, chemical diffusion coefficient and thermodynamic enhancement factor has been determined as a function of lithium content in MOCVD TiS 2 films. The films were deposited in a cold-wall reactor at $7.5 \mathrm{mbar}, 207$ and $250^{\circ} \mathrm{C}$, and a feed gas composition of $0.25 \mathrm{vol} \% \mathrm{TiCl}_{4}$ and $1.4 \mathrm{vol} \%$ hexamethyldisilathiane. The films differ markedly in microstructure. Electrochemical measurements include GITT and impedance spectroscopy of the cell $\mathrm{TiS}_{2} \mid 1 \mathrm{M} \mathrm{LiClO}_{4}$ in $\mathrm{PC} \mid \mathrm{Li}$. The OCV of the films varies from $2.7 \mathrm{~V}(x=0)$ to $1.9 \mathrm{~V}(x=1.0)$. The chemical diffusion coefficient in the $207^{\circ} \mathrm{C}$ film ranges from $2 \times 10^{-15} \mathrm{~cm}^{2} / \mathrm{s}\left(\mathrm{Li}_{0.01} \mathrm{TiS}_{2}\right)$ to $1.3 \times 10^{-13} \mathrm{~cm}^{2} / \mathrm{s}\left(\mathrm{LiTiS}_{2}\right)$; in the $250^{\circ} \mathrm{C}$ film from $2 \times 10^{-14} \mathrm{~cm}^{2} / \mathrm{s}\left(\mathrm{Li}_{0.02} \mathrm{TiS}_{2}\right)$ to $8.5 \times 10^{-12} \mathrm{~cm}^{2} / \mathrm{s}\left(\mathrm{Li}_{0.66} \mathrm{TiS}_{2}\right)$. The thermodynamic enhancement factor increases for both films with lithium composition from \pm 5 to \pm 50 . The $250^{\circ} \mathrm{C}$ film shows a dip in the thermodynamic enhancement factor at $x \approx 0.4$. Preliminary results on the influence of (MO)CVD conditions on the deposition rate and morphology of $\mathrm{TiS}_{2}$ are presented.
\end{abstract}

\section{Introduction}

Miniaturization of solid-state batteries offers three advantages: a decrease in the internal resistance of the cell; an ability to integrate them with electronic circuitry, and easy amplification of either current or voltage by connecting the cells either parallel or in series. The general advantages of solid-state lithium cells, a high energy density, low self discharge and long shelf life, makes them especially suitable for lowpower microelectronic devices such as read/write memories.

Titanium disulfide is a well-known cathode material for secundary lithium batteries. As the lithium conduction of $\mathrm{TiS}_{2}$ is anisotropic, normal-size cells can suffer from polarization losses due to random crystallite orientation. In micromionic devices, the $\mathrm{TiS}_{2}$ film may be deposited with a favourable crystallite orientation.

The aim of our research is to optimize cathode properties through microstructure control. (MO) CVD is used to deposit the cathode films because it offers a good control over a wide range of microstructures. The aim of the present work was to obtain and characterize amorphous $\mathrm{TiS}_{2}$ films. Although this was not accomplished, some insight was obtained in a wide range of deposition conditions, which will be discussed here. The electrochemical properties of two MOCVD $\mathrm{TiS}_{2}$ films will be presented.

\section{Experimental}

The MOCVD setup is outlined in fig. 1.

The deposition conditions used for $\mathrm{TiS}_{2}$ deposition are summarized in table 1.

Electrochemical measurements were performed on

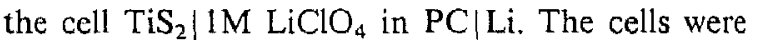
assembled in an argon-filled glove box and sealed from the ambient atmosphere. OCV and galvanostatic intermittent titration (GITT [1]) measurements were done using a EG\&G/PAR 273 potentiostat/galvanostat. Impedance spectroscopy (IS) was performed using a computer-controlled Solartron 1250 frequency response analyser and a Solartron 1286 potentiostat. All measurements were performed at room temperature. The impedance spectra were fit with a non-linear least square fitting programme developed by B. Boukamp at the University of Twente. 


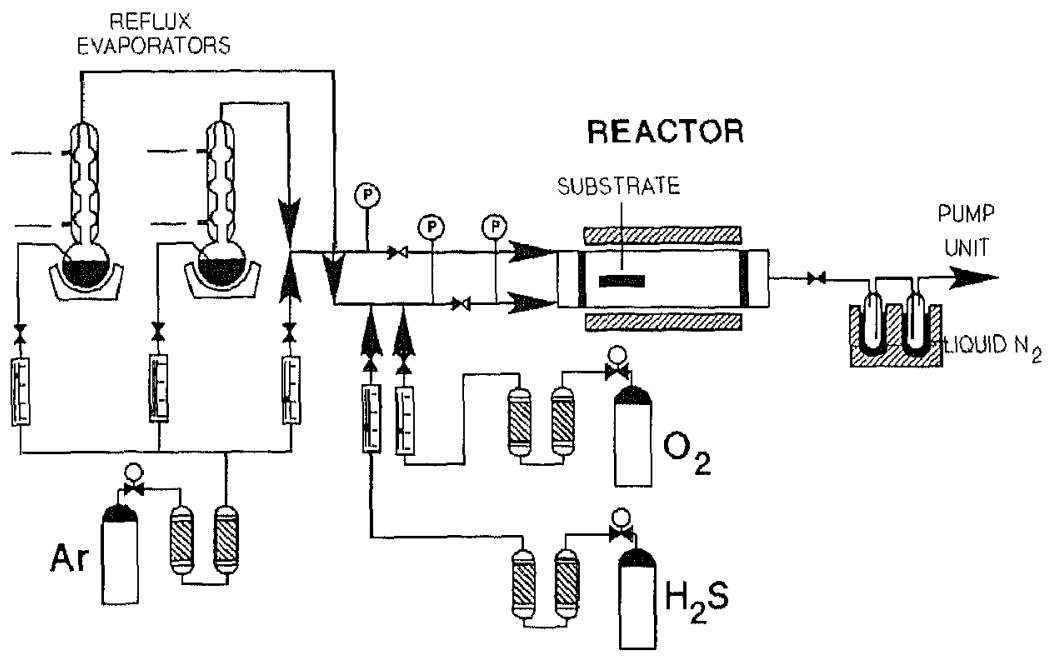

Fig. 1. (Metallorganic) chemical vapour deposition setup.

Table 1

Deposition conditions for the (MO)CVD of $\mathrm{TiS}_{2}$.

\begin{tabular}{|c|c|c|c|c|}
\hline \multicolumn{5}{|c|}{ Feed gas composition (Ar carrier gas) } \\
\hline \multicolumn{2}{|c|}{$11 \mathrm{vol} \% \mathrm{H}_{2} \mathrm{~S} ; 0.38 \mathrm{vol} \% \mathrm{TiCl}_{4}{ }^{\text {a) }}$} & & \multicolumn{2}{|c|}{1.4 vol $\% \mathrm{HMDST}^{\mathrm{b})} ; 0.25 \mathrm{vol} \% \mathrm{TiCl}_{4}$} \\
\hline $\begin{array}{l}\text { Pressure } \\
\text { (mbar) }\end{array}$ & hot-wall $\left({ }^{\circ} \mathrm{C}\right)$ & Reactor type & hot-wall $\left({ }^{\circ} \mathrm{C}\right)$ & cold-wall $\left({ }^{\circ} \mathrm{C}\right)$ \\
\hline 20 & $310,375,455$ & & 250,350 & \\
\hline 7.5 & & & $200-400^{\text {c) }}$ & $200-350^{c)}$ \\
\hline
\end{tabular}

a) Merck, $>99 \%$.

b) Hexamethyldisilthiane $\left.\left(\mathrm{CH}_{3}\right)_{3}-\mathrm{Si}-\mathrm{S}-\mathrm{Si}-\left(\mathrm{CH}_{3}\right)_{3}\right)$ ("purum", Fluka).

c) Temperature intervals of $50^{\circ} \mathrm{C}$.

\section{Results}

\subsection{Process parameters and microstructure}

Films deposited with hexamethyldisilathiane (HMDST, $\left.\left(\mathrm{CH}_{3}\right)_{3}-\mathrm{Si}-\mathrm{S}-\mathrm{Si}-\left(\mathrm{CH}_{3}\right)_{3}\right)$ do not grow on glass substrates, whereas films deposited with $\mathrm{H}_{2} \mathrm{~S}$ and $\mathrm{TiCl}_{4}$ do. Cold wall experiments at 7.5 mbar yield an activation energy of $43 \mathrm{~kJ} / \mathrm{mol}$ for the reaction of $\mathrm{TiCl}_{4}$ and HMDST (fig. 2). Fig. 3 shows that an increase of pressure from 7.5 to 20 mbar does not notably affect the deposition rate (hot wall, HMDST as a sulfur precursor).

XRD shows that all films above $0.5 \mu \mathrm{m}$ consist of hexagonal $\mathrm{TiS}_{2}$. The (preferred) orientation in the $\mathrm{TiS}_{2}$ film appears to be a function of either temper-

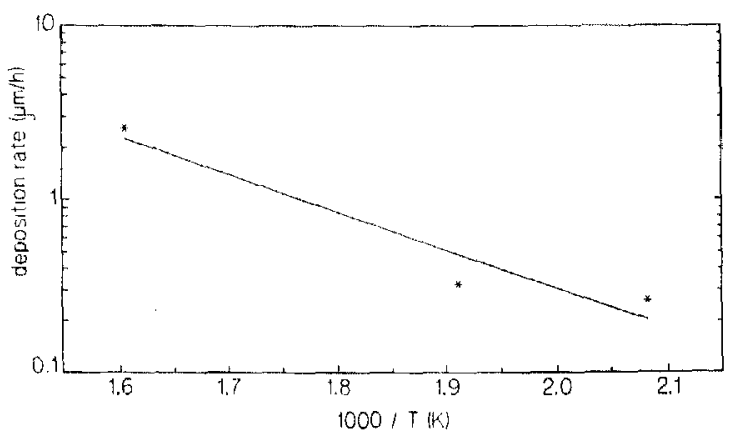

Fig. 2. Deposition rate as a function of temperature for cold-wall depositions from $1.4 \% \mathrm{HMDST}$ and $0.25 \% \mathrm{TiCl}_{4}$ at $7.5 \mathrm{mbar}$. 


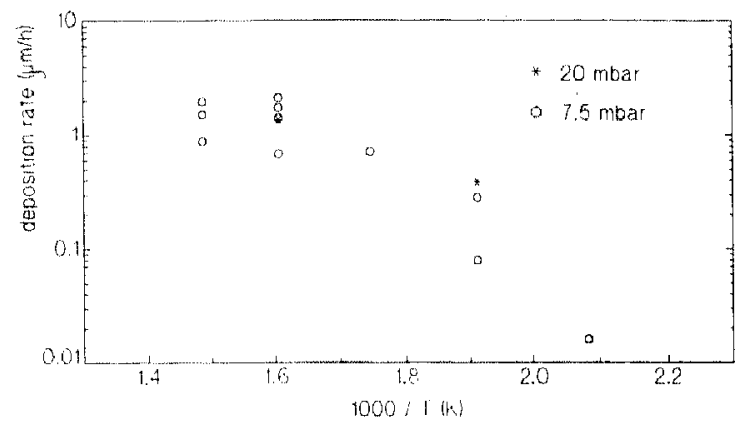

Fig. 3. Deposition rates at 7.5 and 20 mbar. Hot-wall depositions from $1.4 \% \mathrm{HMDST}$ and $0.25 \% \mathrm{TiCl}_{4}$.

ature of thickness. A very favourable orientation was found in a $5.4 \mu \mathrm{m}$ film deposited at $350^{\circ} \mathrm{C}$ and 20 mbar with HMDST; while almost no preferred orientation was seen in a $1.54 \mu \mathrm{m}$ film deposited at $250^{\circ} \mathrm{C}$. The same effect was observed for films de- posited from $\mathrm{H}_{2} \mathrm{~S}$ and $\mathrm{TiCl}_{4}$ : a $1.5 \mu \mathrm{m}$ film deposited at $455^{\circ} \mathrm{C}$ has a favourable orientation, whereas at $357^{\circ} \mathrm{C}(0.5 \mu \mathrm{m})$ the crystallites are preferably orientated with their conducting planes parallel to the substrate. This seems to be consistent with two earlier observations. Kikkawa [2] found a favourable orientation in PE-CVD films thicker than $0.5 \mu \mathrm{m}$; Kanehori [3] obtained an improved orientation with increasing temperature up to $550^{\circ} \mathrm{C}$ and constant deposition time (hence increasing film thickness).

In spite of their varying preferred orientations, all films show a similar morphology. Only the film deposited at $207^{\circ} \mathrm{C}$ and $7.5 \mathrm{mbar}$ from $\mathrm{TiCl}_{4}$ and HMDST showed a different morphology (fig. 4). A typical cross-section is shown in fig. 5 . The crystallite size of $\mathrm{TiS}_{2}$ films decreases with decreasing temperature or pressure.

The porosity of the films is determined by the de-
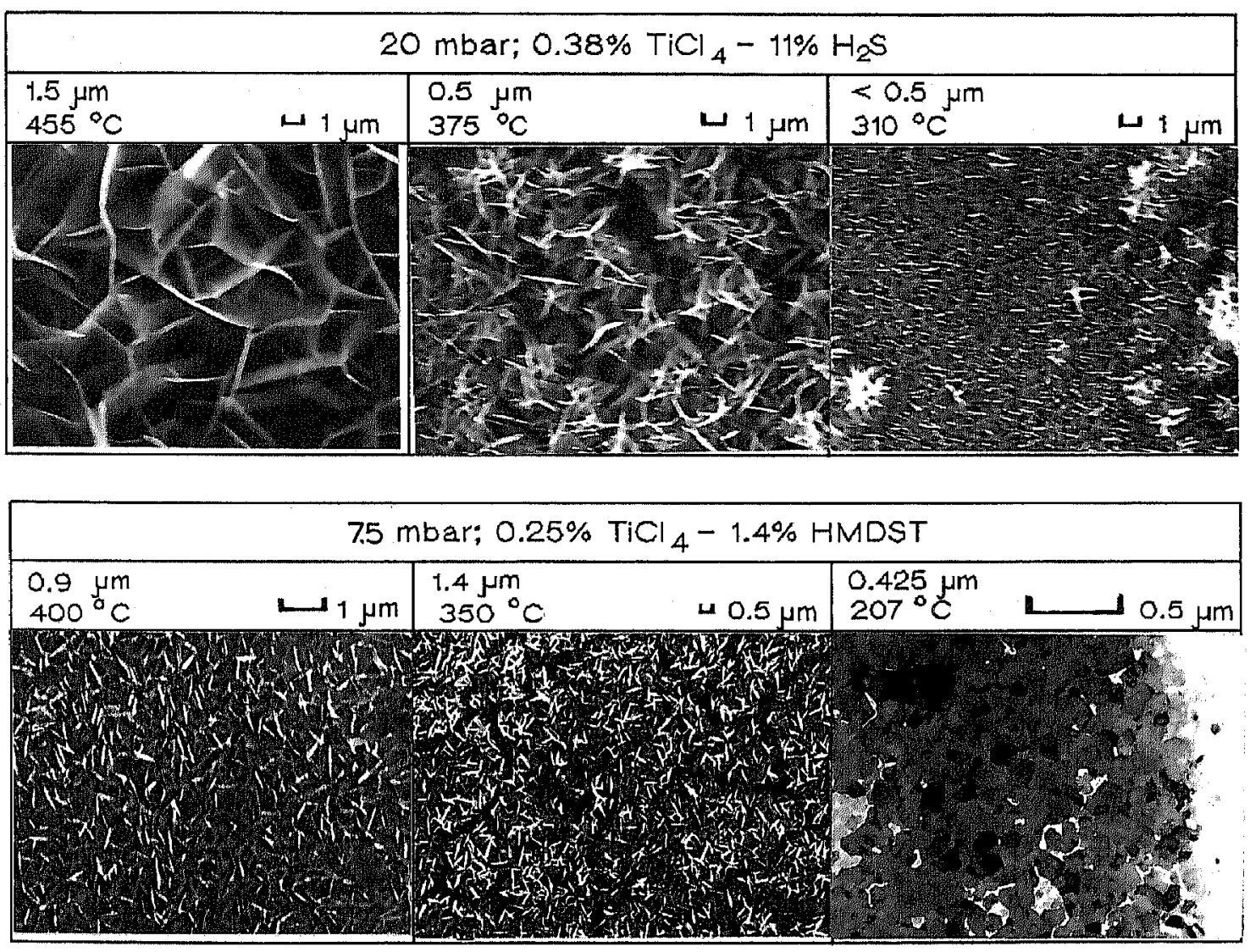

Fig. 4. SEM pictures of (MO)CVD films of $\mathrm{TiS}_{2}$. 


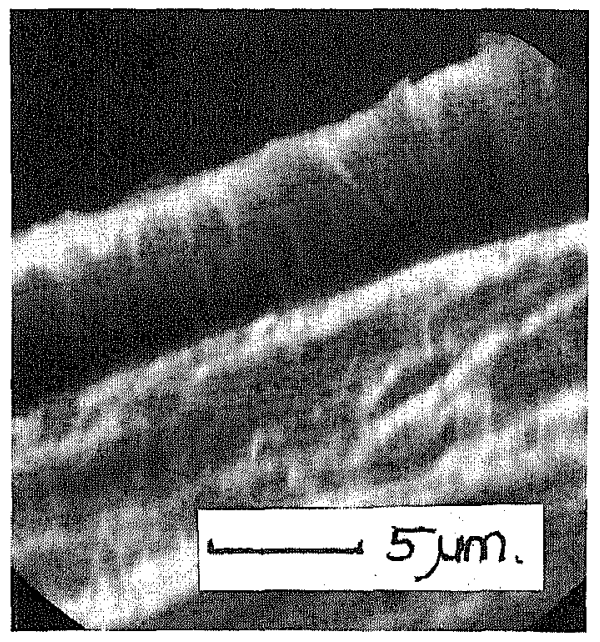

Fig. 5. Cross-section of a $\mathrm{TiS}_{2}$ film with a porosity of $10 \%$ (HMDST, $350^{\circ} \mathrm{C}, 20$ mbar, hot wall).

position conditions. So far, only two samples have been analyzed, deposited at 20 mbar and 250 or $350^{\circ} \mathrm{C}$ with HMDST in a hot wall reactor. The porosity has been determined from weight and thickness of the films. The $250^{\circ} \mathrm{C}$ sample has a porosity of $30 \%, 350^{\circ} \mathrm{C}$ sample $10 \%$. It is not yet known whether this effect is caused by temperature or de- position time. Porosity analyses of all films is in preparation.

\subsection{Electrochemical properties}

Electrochemical measurements were performed on $\mathrm{TiS}_{2}$ films deposited from HMDST and $\mathrm{TiCl}_{4}$ at 7.5 mbar in a cold-wall reactor. The deposition temperatures are 207 and $250^{\circ} \mathrm{C}$. SEM micrographs of the film are given by fig. 6 .

Fig. 7 presents the $\mathrm{OCV}$ of the films versus lithium content. Fig. 8 shows the thermodynamic enhancement factor as it was derived from the OCV versus

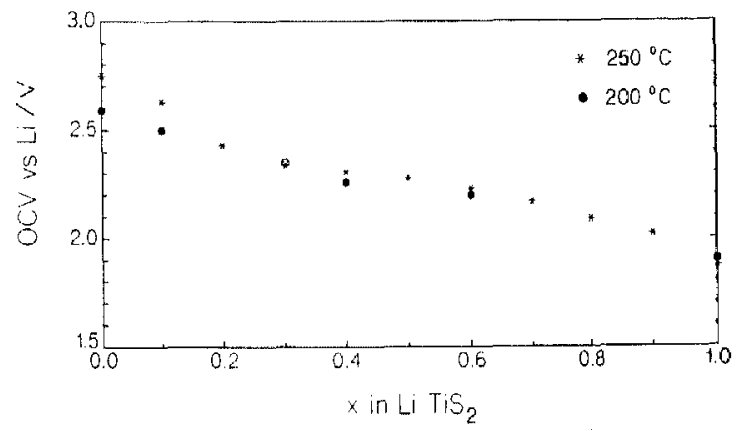

Fig. 7. $\mathrm{OCV}$ versus $\mathrm{Li}$ of $\mathrm{TiS}_{2}$ films deposited at 207 and $250^{\circ} \mathrm{C}$ from HMDST and $\mathrm{TiCl}_{4}$.

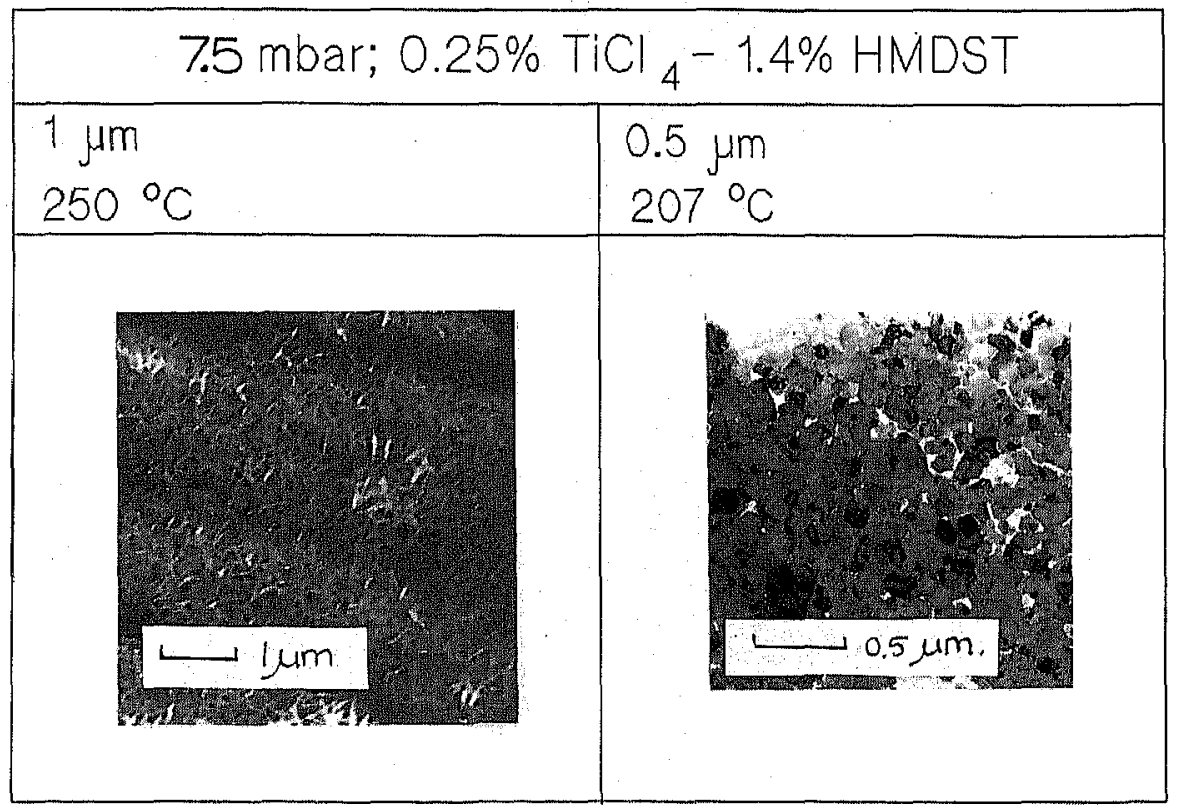

Fig. 6. Morphology of $\mathrm{TiS}_{2}$ deposited from $\mathrm{HMDST}$ and $\mathrm{TiCl}_{4}$ at $207^{\circ} \mathrm{C}$ and $7.5 \mathrm{mbar}$. 


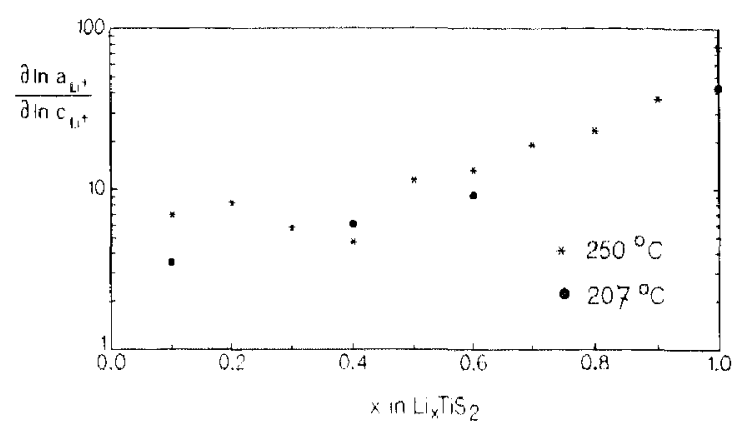

Fig. 8. Thermodynamic enhancement factor of the 250 and $207^{\circ} \mathrm{C}$ $\mathrm{TiS}_{2}$ films.
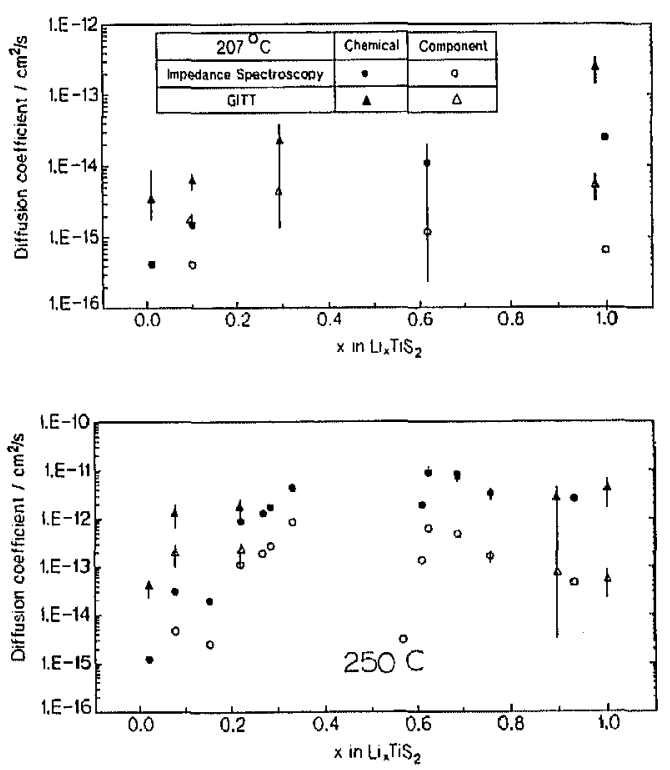

Fig. 9. Chemical and component diffusion coefficients of the 250 and $207^{\circ} \mathrm{CTiS}_{2}$ films.

lithium content [1]. Fig. 9 shows the chemical and component diffusion coefficients in both samples, determined with both GITT and impedance spectroscopy.

\section{Discussion}

The variation of the chemical diffusion coefficient in the $250^{\circ} \mathrm{C}$ film seems to agree well with values found by Zehnder et al. [4] in an X-ray amorphous $\mathrm{ARE}-\mathrm{TiS}_{2}$ film. However, our values are an order of magnitude larger. Despite that, they still are signif- icantly lower than the diffusion coefficient in pressed powder $\mathrm{TiS}_{2}\left(5.6 \times 10^{-9} \mathrm{~cm}^{2} / \mathrm{s}\right)$. The variation of diffusion coefficient with lithium content appears to be a unique property of thin films, as values in $\mathrm{TiS}_{2}$ powder are no function of lithium content [5].

The lithium conduction of the $207^{\circ} \mathrm{C}$ sample is considerably lower than that of the $250^{\circ} \mathrm{C}$ sample. This may be caused by a difference in preferred crystallite orientation. The TEM micrograph of the $207^{\circ} \mathrm{C}$ sample shows a clearly random orientation, whereas the $250^{\circ} \mathrm{C}$ sample may have some preferred orientation. A different possible cause of the difference in lithium conduction may be the effect of different surface structures. The results of both GITT and IS depend sensitively on the current exchange surface (in fact, the calculated value of the diffusion coefficient is inversely proportional to the square of the surface). The current exchange surface was approximated with the geometrical surface of the films. Considering the anisotropy of the material, and the large difference in morphology of the films, the current exchange surface of both films may be very different. Moreover, the current exchange surface is likely to be much smaller than the geometrical surface. A smaller surface would mean that the actual diffusion coefficients are higher than the ones given here, and therefore closer to the values measured in powder $\mathrm{TiS}_{2}$ and unit crystals.

Fig. 9 shows that there can be a considerable difference between the results of IS and GITT, respectively. This difference may be the result of either the interpretation of the impedance spectra or polarization effects due to the anisotropical conduction of $\mathrm{TiS}_{2}$, as will be discussed briefly below.

Impedance spectroscopy only yields reliable results in case of well interpretable spectra. An example of such a spectrum is given in fig. 10. This spectrum can readily be fit by a physically well justified equivalent circuit. In other cases, such as the spectrum in fig. 11, data have been obtained from the part of the spectrum with $45^{\circ}$ and interpreted as the $45^{\circ}$ slope of a T-element. This element describes finite-length diffusion through a medium with a nontransmissive boundary [6].

Polarization effects due to anisotropy may give erroneous results with both IS and GITT measurements. In the case of thin-film mixed conductors, the two measurement techniques are essentially based 


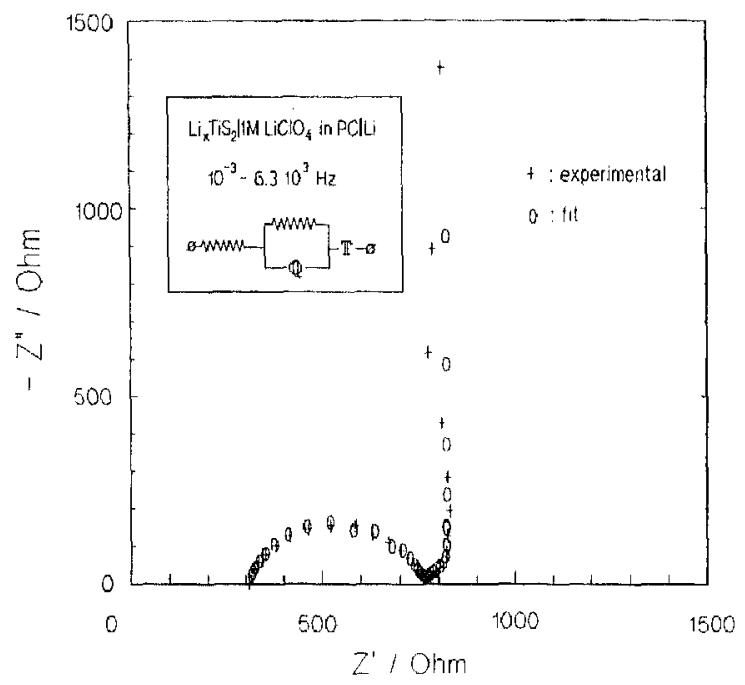

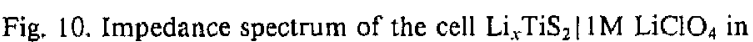
PClLi.

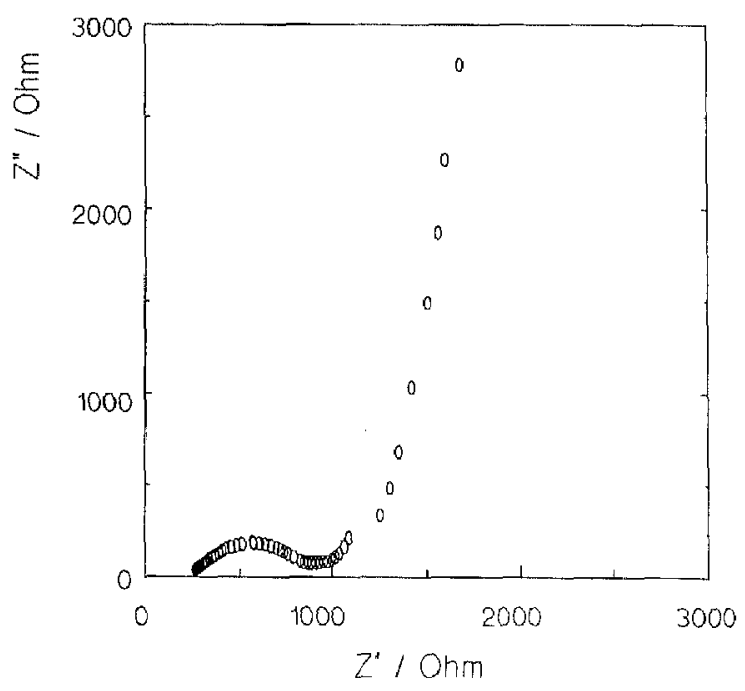

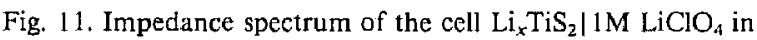
PC $\mid \mathrm{Li}$.

on the same principle: the mathematical description of the polarization of a finite-length mixed conductor due to lithium diffusion. The only difference is that IS describes the response to an ac current as a function of frequency, and GITT the response to a dc current pulse. From this it is clear that polarization due to unfavourably oriented crystallites can cause serious errors in the determination of the diffusion coefficient with either method.
GITT measurements in ranges of lithium content where there is but little influence of lithium content on the OCV are quite sensitive to measurement errors on the OCV of the cell before and after the current pulse.

\section{Conclusions}

This preliminary study has shown that there is a need of accurate models and microstructural analyses of pourous, rough and anisotropically conducting electrodes. These descriptions will allow systematic optimization of cathode properties a correct interpretation of GITT and IS results.

\subsection{Future research}

The work presented here will be extended further. TGA measurements of the stoichiometry of the films are in preparation, as well as a systematic study of both porosity and orientation as a function of process conditions.

\section{Acknowledgement}

The authors wish to express their gratitude to $\mathrm{Mr}$. J.F. van Lent and Mr Ing. N.M. van der Pers of the Materials Science Department of our university for their XRD analyses. Mr. C.D. de Haan of the same Department is acknowledged for his help with the TEM/ED analyses.

\section{References}

[1] W. Weppner and R.A. Huggins, J. Electrochem. Soc. 124 (1977) 1569.

[2] S. Kikkawa, R. Shimanouchi-Futagami and M. Koizumi, Appl. Phys. A 49 (1989) 105.

[3] K. Kanehori, K. Miyauchi and T. Kudo, European Patent 0103470A1, March 21, 1984.

[4] D. Zehnder, C. Deshpandey, B. Dunn and R.F. Bunshah, Solid State Ionics $18 / 19$ (1986) 813.

[5] S. Basu and W.L. Worrell, in: Fast Ion Transport in Solids, eds. P. Vashishta, J.N. Mundy and G.K. Shenoy (NorthHolland, Amsterdam, 1979) p. 149

[6] I.D. Raistrick, J.R. Macdonald and D.R. Franceschetti, in: Impedance spectroscopy, ed. I.R. Macdonald (Wiley, New York, 1987) p. 59. 